\title{
Area based measures of social and economic circumstances: cause specific mortality patterns depend on the choice of index
}

\author{
G Davey Smith, E Whitley, D Dorling, D Gunnell
}

Indices of deprivation based upon the characteristics of areas of residence are widely used in epidemiology and public health, and have a number of possible applications. Firstly, they may be used when data describing a person's socioeconomic circumstances have not been, or cannot be, collected directly. ${ }^{1}$ Secondly, they may inform the distribution of health service resources, for primary care, community health services and hospital services. ${ }^{2}$ Thirdly, in ecological studies examining the effects of local environmental conditions on health they allow investigators to control for possible socioeconomic confounding. ${ }^{3}$ Lastly, they can be used when the main analytic interest lies in the effects of characteristics of place of residence on health. ${ }^{4}$

\section{Methods and Results}

As the particular socioeconomic and demographic characteristics of areas that are related to ill health could differ for different diseases we have compared how two indices-the Townsend index of deprivation and a measure developed by Congdon, which has been referred to as an anomie index ${ }^{5}{ }^{6}$-relate to cause specific mortality. The first of these indices was developed as a measure of deprivation; the second as a measure of social fragmentation, based on Durkheim's theoretical concept of social integration. As Durkheim's concept of social integration differs from his notion of anomie we refer to the Congdon measure as an index of social fragmentation. ${ }^{7}$ Mortality data from 1981-1992 for 633 parliamentary consistencies of Great Britain (as defined in 1991) were used. Townsend deprivation score was based on 1981 and 1991 census data regarding unemployment, car ownership, overcrowded housing and housing tenure. The social

22 August 2000

Table 1 Correlation between indices and SMRS

\begin{tabular}{|c|c|c|c|c|}
\hline & \multicolumn{2}{|c|}{ Simple correlations } & \multicolumn{2}{|c|}{ Partial correlations } \\
\hline & Townsend & $\begin{array}{l}\text { Social } \\
\text { fragmentation }\end{array}$ & Townsend & $\begin{array}{l}\text { Social } \\
\text { fragmentation }\end{array}$ \\
\hline \multicolumn{5}{|l|}{ Women } \\
\hline All cause & 0.82 & 0.35 & 0.85 & -0.50 \\
\hline $\mathrm{CHD}$ & 0.66 & 0.12 & 0.81 & -0.62 \\
\hline Stroke & 0.58 & 0.12 & 0.68 & -0.46 \\
\hline Lung cancer & 0.81 & 0.51 & 0.73 & -0.12 \\
\hline Stomach cancer & 0.60 & 0.15 & 0.69 & -0.45 \\
\hline Suicide & 0.38 & 0.58 & -0.04 & 0.48 \\
\hline Cirrhosis & 0.63 & 0.56 & 0.40 & 0.23 \\
\hline \multicolumn{5}{|l|}{ Men } \\
\hline All cause & 0.87 & 0.46 & 0.86 & -0.40 \\
\hline CHD & 0.67 & 0.13 & 0.80 & -0.60 \\
\hline Stroke & 0.67 & 0.24 & 0.71 & -0.40 \\
\hline Lung cancer & 0.84 & 0.44 & 0.82 & -0.34 \\
\hline Stomach cancer & 0.60 & 0.15 & 0.69 & -0.45 \\
\hline Suicide & 0.58 & 0.71 & 0.18 & 0.53 \\
\hline Cirrhosis & 0.70 & 0.67 & 0.45 & 0.36 \\
\hline
\end{tabular}

fragmentation index was derived from 1981 and 1991 census data on private renting, single person households (aged <65), unmarried persons, and mobility in the previous year. Averages of these scores in 1981 and 1991 were used. The Townsend and social fragmentation index were reasonably strongly correlated; $r=$ 0.7. Table 1 presents correlations between the two indices and death from several illustrative causes, with simple correlations and partial correlations - with each index controlled for the other index-being presented.

While both Townsend and social fragmentation indices are associated with all cause mortality the association of the former is of considerably greater magnitude. Partial correlation analysis leaves the association between all cause mortality and Townsend deprivation unchanged, whereas the direction of association with social fragmentation is actually reversed. For three causes of death strongly related to Townsend deprivation - coronary heart disease, stroke and stomach cancer-the associations with social fragmentation are small to moderate and these reverse after controlling for Townsend deprivation score. For suicide, on the other hand, the association with social fragmentation is of greater magnitude than with Townsend deprivation, a finding amplified in the partial correlation analysis. Cirrhosis mortality is equally related to social fragmentation and Townsend deprivation.

\section{Comment}

These findings suggest that socioeconomic and demographic characteristics of areas have specific associations with particular forms of ill health and death. Socioeconomic deprivation is related to overall mortality rates and to cardiovascular disease, lung and stomach cancer mortality: causes of death known to be strongly related to low socioeconomic position. Controlling for social fragmentation has little effect on these associations. Social fragmentation, on the other hand, shows inverse associations with these causes of death once deprivation is controlled for. Suicide - the cause of death most plausibly linked to social disintegration-is more strongly associated with the fragmentation score than with general levels of deprivation. Social fragmentation could be expected to be related to use of legal and proscribed drugs and in these data this seems to be the case for alcohol consumption, as reflected in cirrhosis mortality.

There has been relatively little development of different area-based indices of social circumstances that are hypothesised to have differential influences on particular health outcomes. 
KEY POINTS

- An index of social fragmentation relates more strongly to suicide mortality than does a generic deprivation index, while the reverse is the case for all cause and cardiovascular mortality.

- Different area-based indices of socioeconomic circumstances have different associations with mortality rates from different causes.

- Theoretically grounded area-based indices should be developed that relate to particular health problems.

An exception is the use of historical and current measures of social circumstances, where it has been shown that stroke, stomach cancer and respiratory disease mortality seem to be related to early life socioeconomic conditions in within country and cross national ecological studies, ${ }^{8-10}$ in agreement with findings from prospective studies of individuals. ${ }^{11}$ This correspondence in findings between ecological and individual level studies suggests that they reflect underlying causal processes that can be indexed through specific area-based measures (in this case indices relating to social circumstances during early life) or through collecting the relevant information on people. The notion that specific social factors are related to particular causes of death has also been examined in time series analyses, which show plausible differential associations, for example the divorce rate being strongly positively related to suicide and cirrhosis mortality and negatively related to stomach cancer mortality. $^{12}$
Socioeconomic data have been used to provide evidence on a wide variety of human experiences ranking from levels of misery to scales of isolation, the effects of racism, feelings of contentment, freedom, opportunity and general happiness. To continue to simply use socioeconomic data to produce measures of deprivation as a unidimensional and purely cross sectional phenomenon is to ignore the wealth of other aspects of peoples' lives that effect their health and are of great potential importance for particular conditions.

Funding: none.

Conflicts of interest: none.

1 Danesh J, Gault S, Semmence J, et al. Postcodes as useful markers of social class: population based study in 26,000 British households. BMF 1999;318:843-4.

2 Sheldon TA. Formula Fever: allocating resources in the NHS. BMF 1997;315:964.

3 Elliott P, Hills M, Beresford J, et al. Incidence of cancer of the larynx and lung near incinerators of waste solvents and oils in Great Britain. Lancet 1992;339:854-8.

4 MacIntyre S, MacIver S, Sooman A. Area, class and health: should we be focusing on places or people? fournal of Social should we be focusing on
Policy 1993;22:213-34.

5 Colicy 1993;22:213-34. small-area study. Urban Studies 1996;33:137-58.

6 Whitley E, Gunnell DJ, Dorling S, et al. Ecological study of social fragmentation, poverty and suicide. BMF 1999;319: 1034-107.

7 Durkheim E. Le suicide. 1897 Paris. Translated as "Suicide: a study in sociology." London: Routledge and Keegan Paul, 1952 .

8 Ben-Shlomo Y, Davey Smith G. Deprivation in infancy and in adult life: which is more important for mortality risk? Lancet 1991;337:530-4.

9 Guallar-Castillon P, Artalejo FR, Banegas JRB, et al. Factores ambientales en la vida temprana y nivel socioeco-

10 Leon DA, Davey Smith G. Infant mortality, stomach cancer, stroke and coronary heart disease: ecological analysis. $B M \mathcal{F}$ 2000;320:1705-6.

11 Davey Smith G, Hart C, Blane D, et al. Adverse socioeconomic conditions in childhood and cause specific adult mortality: prospective observational study. $B M \mathcal{F}$ 1998;316:1631-5

12 Leenaars AA, Lester D. Social factors and mortality from NASH in Canada. Crisis 1998;19/2:73-7. 